Indexed by

\title{
Scopus
}

\section{FREQUENCY CHARACTERISTICS OF IN CYLINDER PRESSURE OF A GASOLINE ENGINE}

DOAJ

Crossref

\section{Sunny Narayan}

Qassim University, Faculty of Engineering, Mechanical Engineering Department, Buryah, Saudi Arabia

\author{
Vipul Gupta \\ Indus University, Faculty of \\ Engineering, Mechanical \\ Engineering Department, \\ Ahmedabad, India
}

Key words: acoustics, automotive, combustion noise, numerical model

Cite article:

Sunny, N., \& Vipul, G. [2021]. Frequency characteristics of in cylinder pressure of a gasoline engine. Journal of Applied Engineering Science, 19(1) 92 - 97. DOI:10.5937/jaes0-27156

Online aceess of full paper is available at: www.engineeringscience.rs/browse-issues 


\title{
FREQUENCY CHARACTERISTICS OF IN CYLINDER PRESSURE OF A GASOLINE ENGINE
}

\author{
Sunny Narayan ${ }^{1 *}$, Vipul Gupta ${ }^{2}$ \\ ${ }^{1}$ Qassim University, Faculty of Engineering, Mechanical Engineering Department, Buryah, Saudi Arabia \\ 2Indus University, Faculty of Engineering, Mechanical Engineering Department, Ahmedabad, India
}

This presented work analysis of effects of changes in various injection parameters on development of combustion pressure development and noise emissions from engines. Scope of using non-intrusive diagnosis technique has been analyzed by using changing various locations of microphone around the engine. In particular the noise emissions from engines were found to be dependent on quantity of fuel injected inside cylinder. Various characteristic frequency ranges of contributing sources have been identified. Time-Frequency analysis has shown onset of various events associated with working of engine. Based on the identification of various frequency bands, it is possible to device suitable filters in order to extract more information about combustion and motion based noise which is done in later part of this work. It may be used as an effective tool for condition monitoring of engines in order to gain fuel economy. Suitable structural modifications of engine may be also done in order to improve its performance on various noise and vibration benchmarks

Key words: acoustics, automotive, combustion noise, numerical model

\section{INTRODUCTION}

Various diagnosis methodologies allow effective monitoring of combustion engines in order to allow preventive maintenance and hence allow ability to detect various faults before it can cause any actual damage to machine. The early detection of faults has both advantages both in terms of cost as well as time. These methodologies allow the downtime of maintenance to be scheduled, prevent sudden shutdown of machines or risks of any potential injury to operators. Diesel engine pressure, vibrations and noise emissions data is a rich source of information about physical conditions and operational parameters [1]. The following section provides details about various diagnosis methodologies adopted in case of diesel engines for condition methodologies.

A. Vibration monitoring -It is most commonly used methodology, but effective location of transducer is a big challenge as mixing of signals may occur due to different transmission paths. Vibration signals can be analyzed by frequency spectrum, peak or RMS values. These can be used to monitor various imbalances, bearing damage or shaft misalignments [1].

B. In cylinder pressure monitoring- Data about cylinder pressure analysis provides information about injector faults, wear, valve problems, incorrect injection timings and hence overall combustion efficiency of engines, however high temperature conditions make various pressure sensors expensive with short life time [2].

C. Noise emissions - Noise levels are perceived by the humans as the air pressure oscillations reach human ears which leads to the motion of the ear drums. Various sound features can be analysed by means of sound pressure levels $(\mathrm{SPL})$ and frequency with equal loud- ness contours. In order to obtain the levels which bears a closer relationship to loudness judgment than the sound pressure levels, three different networks of frequency weighting $(A, B$, and $C)$ were incorporated into various sound level meters with the A-weighting most closely matches the human ear [3].

Due to higher compression ratios, diesel engines are known to produce higher noise emissions as compared to gasoline engines [4,5]. Higher compression ratio increases various forces on piston assembly at the ignition time that results in overall increase in vibrations of engine structure. Overall this leads to increase in noise emissions from engine. Due to large number of external effects the acceleration and noise emissions data may become contaminated leading to complexities. Hence various signal processing methods can reveal information about these events which have fixed time of occurrence depending upon the crank mechanism of engine. These methods Short Time Fourier Transformations (STFT), Wavelet Transformation (WT), Bilinear Time-frequency Distribution (BTFD) [6]. Winger -Ville distribution (WVD), Born -Jordan distribution (BJD) and Choi-Williams distribution (CWD) are commonly used BTFD methods [7]. When these methods are applied to transient signals, large ripples are produced on the envelopes which may lead to loss of information [8]. However, these methods have better frequency as well as time resolutions when compared to conventional Fourier transformations. In this part of work some of the commonly used signal processing techniques have been discussed. Various important properties of these methods have been presented, and finally their performance was evaluated by application on the data acquired from engine, operating it at different testing conditions. 


\section{THEORY AND EXPERIMENTATION}

\section{A. Power spectral density function}

This function $\left(\Psi^{2}\right)$ denotes a random process which provides the frequency composition of data in terms of its mean square value [9]. The mean square value of a time sample in frequency range $[\omega, \omega+\Delta \omega]$ can be obtained by passing sample through a band pass filter with sharp cut off frequency features and then computing the average of squared output from filter. The average square value approaches mean square value as $T \rightarrow \infty$.i.e.

$\Psi^{2}(\omega, \Delta \omega)=\operatorname{Lim}_{\Delta x \rightarrow \infty} \frac{\int_{0}^{T} x^{2}(t) d t}{T}$

\section{B. Time frequency analysis}

The Fourier transformation of a function $f(t)$ in frequency domain can be represented as:

$\mathrm{f}(\omega)=\int_{0}^{t} f(t) e^{-j \omega t} \mathrm{dt}$

This analysis is useful as long as frequency content of signals do not vary with time. Hence time-frequency analysis or wavelet analysis are more suitable [10]. Time-frequency analysis is suitable for analysis of signals having slow frequency changes such as those generated during engine ramp down, whereas wavelet analysis is more suited for fast frequency changes such as those generated during rattle [11]. In the time-frequency analysis the signal is windowed into small intervals and then Fourier transformation is taken for each interval [12].

Length of window can be used to change the resolution of the output signal. A shorter window has higher resolution in time domain, but a poor resolution in frequency domain and vice versa. Higher time resolution at higher frequencies makes it possible to resolve short consecutive events using wavelet transformation. The short time frequency analysis is based on expansion of signal into a set of weighted frequency modulated Gaussian functions and may be represented as:

Where $x(t)$ is input signal \& $h(t-T)$ is window function. Wigner Ville function has following quadratic time-frequency distribution represented by [9]:

$\operatorname{STFT}(\tau, \mathrm{f})=\int_{0}^{T} x(t) h^{*}(t-\tau) e^{-j \omega t} d t$

\section{Wavelet Analysis}

Wavelet analysis maps a signal on joint time -frequency plane and is sensitive towards the transient nature of signals. One of the major drawbacks of various time-frequency processing methods is that they produce ripples, hence making it difficult extract valuable information [13]. During wavelet analysis, the frequency resolution is better at low frequencies whereas the time resolution is better at higher ones. Hence Wavelet analysis results are more accurate as compared with other methods [14]. Using wavelet method, a signal is transformed onto a family of zero mean functions which are known as wavelets.
These have high time resolution and have no cross-term interference. The power spectral density function (PSD) is similar to the short-time-frequency analysis, whereas the wavelet transformation represents a linear transformation.

The squared wavelet transform is called a scalogram. A single scalogram can easily cover audible frequency range with a time resolution of approximately $0.1 \mathrm{~ms}$ for the high-frequency components [11-29].

This makes scalogram more suitable for such various signals like squeak and rattle noise for which a wide range of frequency analysis is needed.

Mathematically for a function $f(t)$, a complex wavelet transform is defined by [15]:

$\operatorname{CWT}(\mathrm{a}, \mathrm{b})=\int_{-\infty}^{+\infty} f(t) \frac{1}{\sqrt{a}} \frac{\psi(t-b)}{a} d x$

Where

$\psi(\mathrm{t}):$ Mother wavelet

$\mathrm{f}(\mathrm{t})$ : Analyzed signal

a: Scaling factor

b: Shifting factor

CWT $(a, b)$ : wavelet coefficients

Both dilation as well as translation parameters in CWT are subjected to variations that makes its use more complex. Discretization of signals can help to reduce this problem to certain extent.

Control of in combustion pressure developed inside combustion chamber is a key aspect of controlling combustion-based noise from engines [1-4]. This may be achieved by use of piezo-resistive sensors to monitor the in-cylinder pressure developed [5]. Rapid pressure rise may lead to structural vibrations in engines that may be analysed using accelerometers $[5,6,7]$. The presented work analyses result from various tests done on a gasoline engine test rig in order to investigate variations in mean frequency of in cylinder pressure development.

Analysis of acoustic spectrum and sound intensity. Was done by Hou [8]. A study of the vibration data from a compression ignition engine operated on blends of diesel and Neem methyl ester was also done [9]. Keskin et al. [10] investigated effects of blends of ethanol-gasoline-oil on engine vibrations [11].

\section{EXPERIMENTAL SECTION}

A gasoline kirloskar rig was tested that had specifications as presented in Table 1.

Table 1: Engine specifications

\begin{tabular}{|c|c|}
\hline Component & Rating values \\
\hline Bore & $67 \mathrm{~mm}$ \\
\hline Stroke & $56 \mathrm{~mm}$ \\
\hline Compression ratio & $4.5: 1$ \\
\hline Power & $2.25 \mathrm{~kW}$ \\
\hline
\end{tabular}


The engine was operated under full load and speed of 1600 RPM and 2000 RPM. An AVL GU13P type transducer was used to acquire the instantaneous in-cylinder pressure data having features presented in Table 2.

Table 2: Pressure transducer specifications

\begin{tabular}{|c|c|}
\hline Range & 0 to 200 Bar \\
\hline Sensitivity & $15.8 \mathrm{p} \mathrm{C} \mathrm{per} \mathrm{Bar}$ \\
\hline Resonant frequency & $130 \mathrm{kHz}$ \\
\hline
\end{tabular}

Microphone was placed around three marked locations $A, B, C$ around the engine as shown in Fig.1.

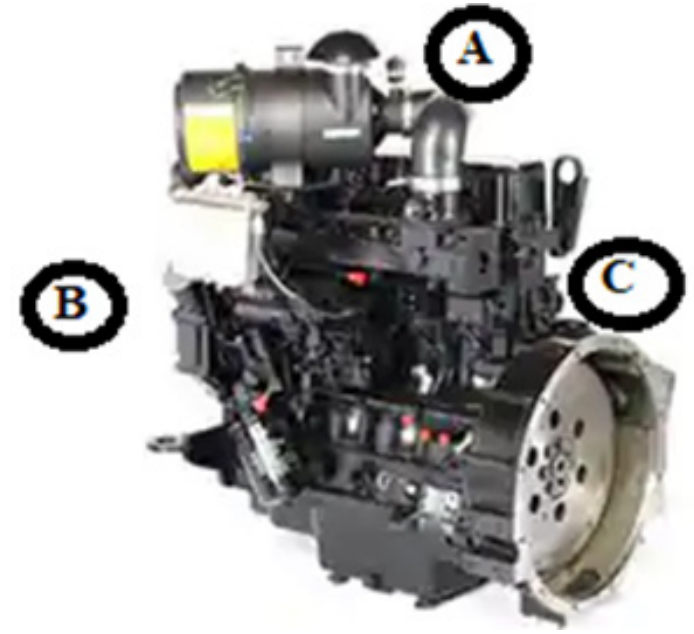

Figure 1: Microphone locations

\section{RESULTS}

Once signals were analyzed, wavelet based time frequency analysis of noise emissions acquired at location A was done, in order to investigate the spectral distribution of energy among various events taking place for a complete cycle as seen in Fig. 2, 3 under full load conditions. These plots show periodicity of various contributing sources clearly characterized by high frequency components below $1 \mathrm{kHz}$ range.

\section{DISCUSSIONS}

The combustion process is responsible for high frequency components in spectrogram and is well represented below $2 \mathrm{kHz}$ range. An increase in speed of engine causes a translation towards higher values, but amplitude of various components does not show significant variations with changes in engine load. Hence another method which is based on study of variations of mean frequency trends was used for analysis of signals [12]. The mean frequency of a signal is given by [13-33]:

fmean $=\frac{\sum_{k=0}^{W} f_{k} P\left(f_{k}\right)}{\sum_{k=0}^{W} P\left(f_{k}\right)}$

Where $P(f k)$ is kth sample of power spectrum and $w$ is frequency band of signal.

The covariance of a given function $x(h)$ can be computed as follows:

$\mathrm{C}$ (h) $=\frac{1}{2 N+1} \sum_{k=-N}^{k=+N} x^{+}(h) x^{+^{\prime}}(h+k)$

Where $x+(h)=x(h)+j x^{h}$ is analytical signal of input $x(h)$ calculated using its Hilbert transformation $x^{h} . x{ }^{\prime}$ is complex conjugate of $x+$.

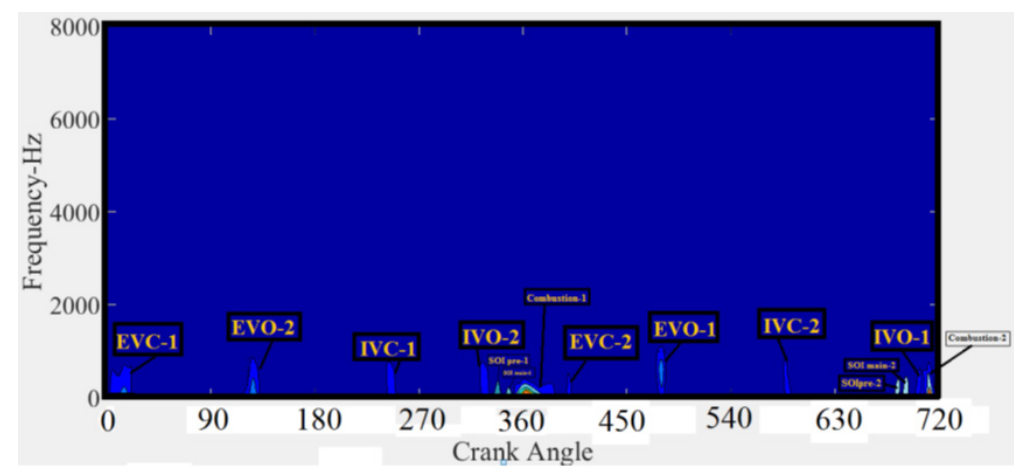

Figure 2: Time-frequency analysis - 1600 RPM

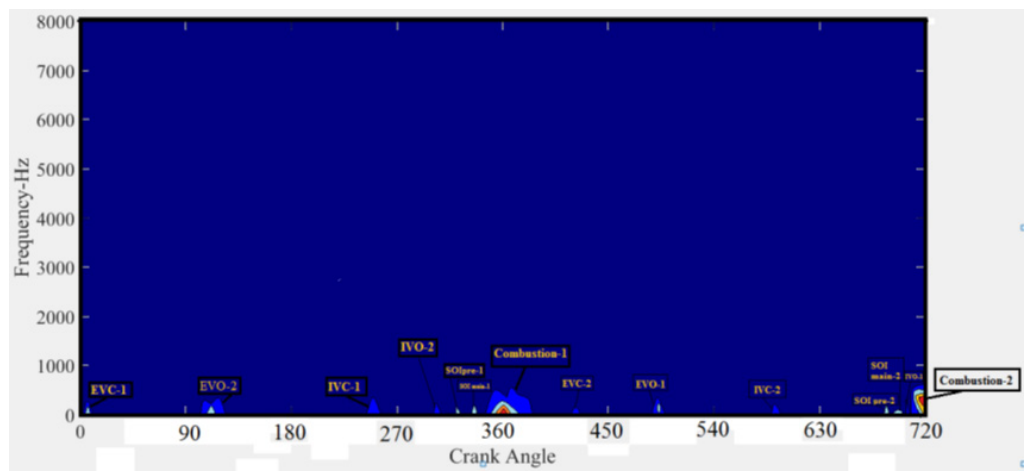

Figure 3: Time-frequency analysis - 2000 RPM 


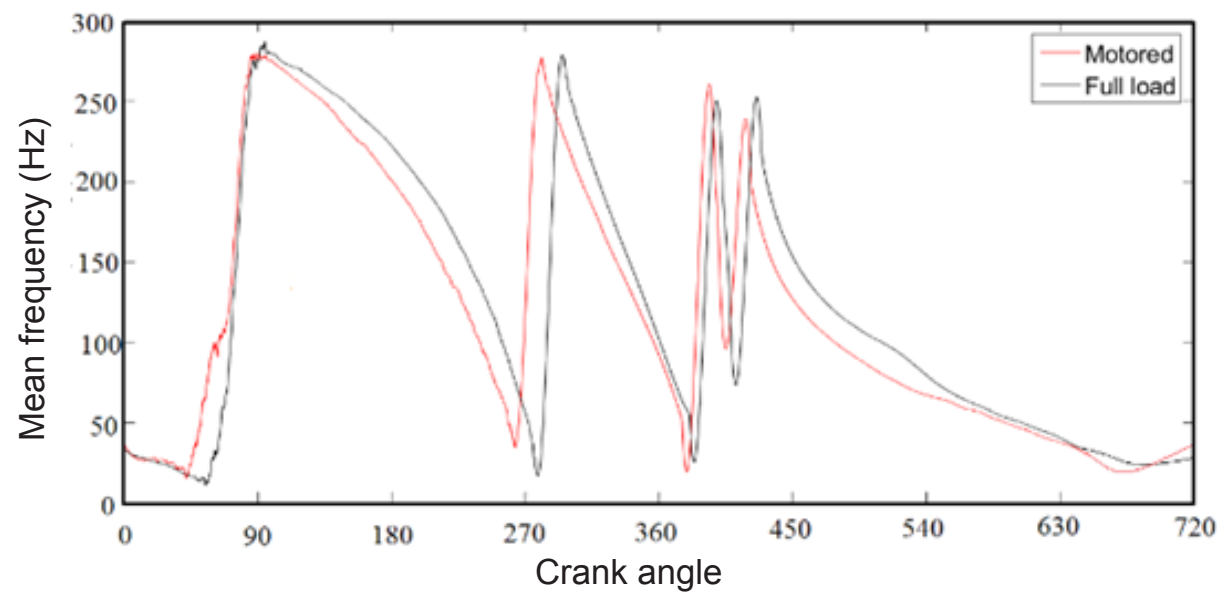

Figure 4: Mean frequency analysis - 1600 RPM

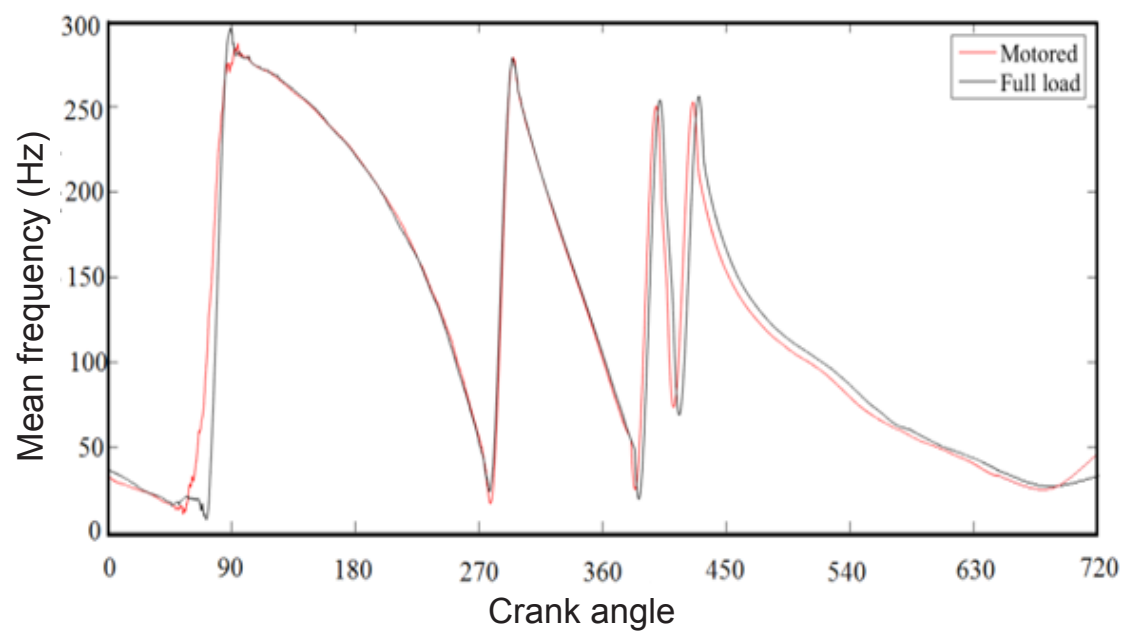

Figure 5: Mean frequency analysis - 2000 RPM

Fig. 4, 5 shows variations in the mean frequency trends for in cylinder pressure signals acquired at location $A$ under full load. All trends show excitation of sources in terms of their frequency contents, their amplitude and locations of crank angles at which they appear. Various trends were found to be same irrespective of load variations. Motored case was observed to reach peak values before full load condition.

\section{CONCLUSIONS}

Pressure developed during engine operation provides important information about diagnosis of combustion process in engines. In this work a novel method that was based on mean frequency distribution was investigated. The proposed methodology can prove to be effective tool for diagnosis of various cyclic events occurring during course of operation of engine.

\section{REFERENCES}

1. Zheng et al. (2002). Internal combustion engine noise analysis time-frequency distribution, Journal of Engineering for Gas Turbines and Power Vol. 124, No. 3, DOI: 10.1115/1.1455639
2. Zhen et al. (2015). Combustion Noise Analysis for Combustion and Fuels Diagnosis of a Compression Ignition Diesel Engine Operating with Biodiesels, Combustion Science and Technology, Vol.187, No.12,1974-1992.

3. Kim et al. (2008). Prediction of interior noise by excitation force of the powertrain based on hybrid transfer path analysis, International Journal off Automotive Technology, Vol. 9, No. 5, 577-583.

4. Biermann et al. (2005). possibilities to improve transient gear shift noise (shift clonk) in a passenger car, International Journal of Automotive Technology, Vol. 6, No. 1, 23-28.

5. Ibarra D., Ramirez-Mendoza R., Lopez E. (2016). A New Approach for Estimating Noise Emission of Automotive Vehicles, Acta Acustica united with Acustica. Vol. 102,930 - 937.

6. C. Yang and T. Feng. (2016). Abnormal Noise Diagnosis of Internal Combustion Engine Using Wavelet Spatial Correlation Filter and Symmetrized Dot Pattern, Applied Mechanics and Materials, Vol. 141, 168-173. 
7. Torregrosa et al. (2007). Combustion noise level assessment in direct injection diesel engines by means of in-cylinder pressure components, measurement science and technology, Vol. 18, No. 7, 2007. IOP publishing Itd.

8. Hou, X., Du, S., Lu, C., Liu, Z., Zheng, H., \& Wu, H. (2007). Sound \& vibration control for a single-cylinder gasoline engine based on parameter optimization of timing-chain system, Proceedings of the Institution of Mechanical Engineers, Part D: Journal of Automobile Engineering, Vol. 232, No. 13,1815-1827,2018., DOI: https://doi.org/10.1177/09544070177444.

9. Madhava Varma B., Ravi Kumar N.1 and Prasanthi G. (2016). International Journal of Automotive and Mechanical Engineering (IJAME), Vol. 13, No.2, 3434 - 3450.

10. Keskin, A. (2010). The Influence of Ethanol-Gasoline Blends on Spark Ignition Engine Vibration Characteristics and Noise Emissions, Energy Sources, Part A: Recovery, Utilization, and Environmental Effects, Vol. 32, No. 20,1851-1860, DOI: 10.1080/15567030902804749

11. Yang et al. (2018). Vibration Characteristics of Compression Ignition Engines Fueled with Blended Petro-Diesel and Fischer-Tropsch Diesel Fuel from Coal Fuels, Energies, Vol. 11, No. 8, 2043, DOl:10.3390/ en11082043

12. Ridsdill-Smith, T.A. (2007). The application of the wavelet transform to the processing of aeromagnetic data, PhD thesis, University of Western Australia. 2000 .

13. Narayan, S. (2014). A review of diesel engine acoustics, FME Transactions, Vol. 42, No. 2, $150-$ 154.

14. Narayan Sunny. (2015). Correlation between in cylinder pressure and noise emissions from engines, Journal of Kones power train and Transport, Vol. 22, No. 1, 243-254.

15. Mahroogi, F.O., Narayan, S., Gupta, V. (2018). Acoustic transfer function in gasoline engines, International Journal of Vehicle Noise and Vibration, Vol. 14 , No. 3, 270-280.

16. Narayan, S., Gupta, V. (2018). Numerical analysis of secondary motion of piston skirt in engines, International Journal of Acoustics and Vibrations, Vol. 23, 557-565.

17. Narayan, S. (2015). Piston slap noise in engines, International Journal of Applied Engineering Research, Vol. 8, No. 14, 1695-1700

18. Narayan,S., (2015). Analysis of Piston Slap Motion, IJAME, Vol. 20, No. 2, 445-450.

19. Narayan, S. (2015). Modeling of Noise Radiated from Engines, SAE Technical Paper 2015-01-0107.
20. M.U. Kaisan, S. Abubakar, B. Ashok, Dhinesh Balasubramanian, S. Narayan, Ivan Grujic \& Nadica Stojanovic (2018). Comparative analyses of biodiesel produced from jatropha and neem seed oil using a gas chromatography-mass spectroscopy technique, Biofuels, Taylor and Francis, DOI: 10.1080/17597269.2018.1537206.

21. Faisal O. Mahroogi, S. Narayan (2020). A recent review of hybrid automotive systems in Gulf Corporation Council (GCC) region, Proceedings of the Institution of Mechanical Engineers, Part D: Journal of Automobile, SAGE Publications, Volume 233, No.14, 3579-3587 DOI:10.1177/0954407019836055

22. S. Narayan. (2019). Combustion monitoring in engines using accelerometer signals, Journal of Vibro-engineering, Vol. 21, No. 6, 1552-1563

23. S. Narayan.(2013). Wavelet analysis of diesel engine noise. Journal of Engineering and Applied Sciences, Vol. 8, No. 8, 255-259., DOI:10.3923/jeasci.2013.255.259

24. Sunny Narayan.(2013). Piston Slap Noise in engines, International Journal of Applied Engineering Research, Vol. 8, No.14,1695-1700.

25. Sunny Narayan.(2013). Effect of dwell time on noise radiated from diesel engine, International Journal of Applied Engineering Research, Vol. 8, No. 11, 13391347.

26. Ali Sulaiman Alsagri, Vipul Gupta, S.Narayan. (2018). Design and analysis of hybrid automotive suspension system, International Journal of Mechanical and Production Engineering Research and Development (IJMPERD), Vol. 9, No. 4, 637-642.

27. Ali Sulaiman Alsagri, Faisal O. Mahroogi, S.Narayan. (2018). Design and analysis of Double Wishbone suspension systems for automotive applications, International Journal of Mechanical and Production Engineering Research and Development (IJMPERD), Vol. 9, No. 4, 1433-1442.

28. S Narayan. (2015). Analysis of noise emitted from diesel engines. Journal of Physics Conference Series 12/2015;662(1):012018., DOI:10.1088/1742659 6/662/1/012018.

29. Faisal O. mahroogi, S. Narayan.(2019). Dynamic-analysis-of-piston-secondary-motion-using FEM method, Proceedings of the 26th International Congress on Sound and Vibration, Montreal bridges, ISSN 2329-3675, ISBN 978-1-9991810-0-0.

30. Narayan, S. (2015). Effects of Various Parameters on Piston Secondary Motion, SAE Technical Paper 2015-01-0709. DOI: https://doi.org/10.4271/201501-0079

31. Grujic, I., Stojanovic, N., Pesic, R., Davinic, A., Narayan, S.(2020). Numerical analysis of IC engine operation with high-pressure hydrogen injection, Transactions of FAMENA, Vol.44, No. 1, pp. 55-66. 
32. Abubakar, S., Anafi, F.O., Kaisan, M.U., Umar, S., Umar, U.A. (2020). Comparative analyses of experimental and simulated performance of a mixed-mode solar dryer, Proceedings of the Institution of Mechanical Engineers, Part C: Journal of Mechanical Engineering Science, Vol. 234,No.7, pp. 1393-1402.
33. Stojanovic, N., Ghazaly, N.M., Grujic, I., Glisovic, J., Narayan, S. (2020).Influence of size of ventilated brake disc's ribs on air flow velocity, International Journal of Advanced Science and Technology, Vol. 29, No.1, pp. 637-647. 